\title{
The reuse and valorisation of rural building heritage
}

\author{
R. Di Giulio, T. Zaffagnini, S. Brunoro, D. Longo \& E. Piaia \\ University of Ferrara, Department of Architecture, Ferrara, Italy
}

\begin{abstract}
This paper provides an introduction to the aims of the EU Villas project (Interreg IIIB Cadses 2000-2006). It entails the improvement and revitalisation of the aesthetic and economic aspects of architectural heritage by creating an evaluation model and defining a compatible strategic tool for re-use, in keeping with the planning criteria and sustainable policies of the CADSES area.

The European countries involved in this research project are developing common strategies to preserve and exploit their environmental and building heritage and to implement cultural-tourism activities. Specific tools have been developed in order to assess and valorise the aesthetic and economic aspects of architectural heritage, taking into account each country's peculiarities (specific problems, users, regulations, etc).

Our research group at the University of Ferrara, Department of Architecture, is studying rural buildings in Emilia Romagna that are insufficiently valorised. The preservation of this heritage can be achieved through economic re-use and the definition of integrated strategies ranging from land planning to sustainable refurbishment techniques. These strategies are presented in this paper.

Keywords: rural building heritage, sustainable tourism, promotional activities, strategies and best practice.
\end{abstract}

\section{Introduction}

When preserved and managed in an appropriate way, cultural heritage can play a decisive role in spatial development. Heritage buildings form an integrated system which characterises the landscape and remain in our collective memory. The landscape is the aesthetic expression of the environment. Therefore, historical buildings provide material evidence of civilisation in their spatial and 
temporal context. The small number of historical buildings in good condition are underused and not efficiently valorised, while the remaining majority is now in an advanced state of disrepair. These problems mainly derive from lack of promotion, abandonment and scarce resources. Most of the buildings are not effectively used. Changes in lifestyle, the fragmentation of landholdings and portioning have led to a lack of private funds for conservation, while public funds are often restricted to other areas. Their preservation can entail sustainable development issues and framework.

\section{The Villas project}

The VILLAS' project focuses on the need to preserve and upgrade the cultural heritage of the CADSES area, an area which contains a wealth of protected buildings.

The main aim of the project consists of improving and revitalising the aesthetic and economic aspects of architectural heritage, which is one of the most relevant components of historical identity, both from a national and European point of view. This will be made possible by creating an evaluation model and developing a compatible re-use strategy tool, in keeping with the planning criteria and spatial policies of the area. The relative planning must also be compatible with the common needs and problems of the target regions. The promotion of cultural heritage as a regional development asset is oriented to ensure cultural heritage protection, survival and promotion, in line with sustainable development ideas, using common methodologies and defining integrated strategies, which range from land planning to sustainable restoration techniques. This will be achieved through the classification of potential evaluated economic uses, the identification of new types of legal restrictions, the upgrading of juridical instruments and establishment of common management methods, in order to improve the effectiveness of resource allocation policies for the renewal and valorisation of cultural heritage architecture. Sixteen partners are involved in this project, each of which focuses on the cultural heritage particular to its landscape: Veneto villas (Veneto Region and Regional Institute of Villas of the Veneto), Emilia Romagna rural homes (University of Ferrara Department of Architecture), Emilia Romagna villas (IBACN - Institute of Cultural Heritage of the Emilia Romagna Region), industrial buildings, rural and walled towns, stately villas and castles (Province of Campobasso), Umbria rocche (Umbria Region), castles and walled cities from the Middle Ages to the Baroque period (Government of Carinthia - Austria), Corfu listed buildings (Municipality of Corfu), Croatia castles (Fund for regional development of the Republic of Croatia, University of Zagreb - Faculty of Architecture, County of Zagreb, County of Krapina-Zagorje, County of Varasdin, County of Pozega-Slavonia, County of Koprivnika-Krizevci). The overall trend of neglect has motivated the partners to develop a sound compatible method that, through the recognition of common traits, will be able to ensure the development, further use and integration of their heritage with current needs. The project will follow on from the analysis of the regulatory, economic and historic context and also the 
definition of a common data collection methodology. This methodology will derive from a comparison with current methods, but above all from the collection of the necessary data for the construction of the analysis matrix and for setting up the evaluation model, as well as for the definition of the buildings on which the promotional network will be based. Once the method has been defined, each partner will then add their own data to the database on the web site, allowing for a general exchange of information. The data collected will be placed on GIS and a number of thematic analysis maps will be produced. At this point we will know which of the heritage buildings are abandoned and which are in good condition, but are in fact underused. An evaluation and operational stage will follow for the first building category, while a valorisation and promotional network will be created for the second.

The University of Ferrara research group analyses the historical heritage represented by the scattered settlements in the rural landscape of Emilia Romagna, especially the area between Bologna and Ferrara. This historical heritage is distributed uniformly throughout the Pianura Padana and is characterised by various types of aggregation in relation to location, materials and use. The main aims of the research are the analysis of the morphological, typological and technological features and the definition of the criteria for evaluating the buildings' suitability for transformation. Moreover, additional research objectives include the creation of an analytical model for the evaluation of the preservation quality, the evaluation - for uniform areas - of the quality of the market demand and of the local requirements, the definition of a refurbishment method so as to allow for the quick interpretation of usage and economical potential, and the definition of the peculiar parameters of the quality/versatility of the building. In the long term, the project is expected to have a positive effect on the regional communities and economy through boosting awareness, cultural tourism, investment possibilities and the amelioration of juridical instruments on a national and European level in a wider sense. Management policies of historical buildings can be reviewed both in theory and practice and the conservation of heritage buildings can be aided through certain forms of economic re-use. Therefore, new types of legal restrictions can be defined and different levels of intended use can be identified. The new forms of economic use must respect the historical and artistic characteristics, and should be sustainable and economically efficient. This can be made possible both by obtaining financial funds for building maintenance, and by providing economic benefits to the surrounding area, while maintaining the historical and architectural features of the historic buildings.

\section{Technical problems linked to re-use, environmental sustainability and the economic sustainability of the operation}

The historic rural building heritage located between Bologna and Ferrara, which does not differ greatly from that which dots the entire Emilia Romagna plain, is characterised by relatively homogeneous settlements which have now been 
clearly encoded $[1,2]$. Generally speaking, they differ in terms of the presence or lack of physical boundaries around the plots belonging to the individual buildings and their outbuildings, groups of buildings of similar dimensions for different uses or building blocks for combined use (residential/productive).

In confirming the existence of three types of agricultural sites in line with the above criteria (open site, closed site and juxtaposed elements), the census carried out as part of the Villas research highlighted a clearly articulated state of preservation through the study of 85 sample cases. The extreme cases see, on the one hand, sites in a state of complete abandonment and, on the other, correctly restored settlements that have once again become productive from an economic point of view thanks to suitable operations on both the building and its surroundings.

The current research aims to investigate and, if possible, draw up an efficient reference model regarding the re-use of these constructions, so as to both safeguard the historical, productive and constructive characteristics of an entire homogeneous rural area, and so as to be a tool for the initial economic evaluation of the operation feasibility and future profitability of the same, based on analogous cases seen to be examples of best practice.

In the light of literature on rural building preservation, and especially following the analysis of many cases (in literature and on the field), it appears that there is no real strategic rule for re-use. A number of planning criteria borrowed from the study of the context and the market opportunities are what ensure a good result in economic terms and as regards the safeguarding of the building and the site as a whole.

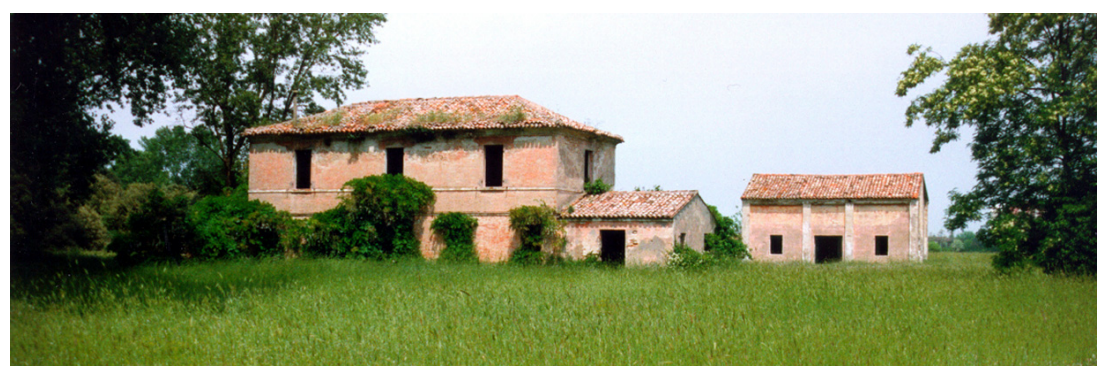

Figure 1: A site in Ferrara district.

\subsection{Technical problems relative to re-use and environmental sustainability}

Rural building is comprised of a relatively limited number of repeated typological models (with variants and stylistic variables that represent local construction methods in territorially and politically homogeneous areas) and a genius loci construction art, which entails the use of construction materials that are easy to find in the immediate [3]. It is also characterised by the development of planning and construction models able to make the most of the climatic conditions of the area, with the development of unwritten rules that are extremely effective as regards the orientation, the distribution of the rooms and the natural hygrothermal control of the constructions. 
From a purely technological point of view, the restoration plan does not therefore involve major technical problems as regards the practical restoration in keeping with the original technical solutions, or for its eco-sustainable execution. The most significant work regards the wooden roofing and floor structures, which are almost always the most deteriorated due to the use of "poor" woods in the original building, such as the almost systematic use of poplar (populus alba) for beams, square section beams, floors, etc. Foundations represent another delicate technical aspect. They are often absent or very shallow, with slight increases in the thickness of the walls just below ground level. They may require extensive and major shoring operations in order to comply with current regulations $[3,5,6]$. Lastly, there are a number of different techniques regarding wall conservation, including specific conservation and restoration techniques (plaster restoration, shaving or sagramatura). They generally involve layered internal solutions, marked by the integration of the existing vertical external closure with thermal insulation and brickwork casing so as to ensure less heat dispersion, which would be impossible with the existing walls.

The operation is made more complex by the close relationship between the intended use of the newly restored building and the building type.

\subsection{Intended use and the economic sustainability of the operation}

The effectiveness or the coherence of the restoration project and the new intended uses of rural buildings is an essential part of compliance with the typological and construction connotations of the existing building. The first parameter to be considered when assessing the suitability - including financial for restoration of a rural building (or group of buildings) lies in the initial examination of the dimensions and volume of the building in relation to the suggested new use. Every intended use entails not just minimum and inescapable dimensional requirements, but also specific structural needs due to hygiene and local building requirements, as well as the infrastructures needed to cater for the new use.

It is therefore important to draw up some good planning rules for application to all the study cases, even before creating an economic evaluation model to indicate the building's potential for restoration. These rules should regard the identification of the parameters that cannot be changed (materials, building systems, the aggregative or expansive logic of the buildings, etc.) and specific dimensional and/or regulatory characteristics relative to the various intended uses.

Therefore, after having identified around a dozen different uses of the surveyed agricultural sites amongst the eighty plus settlements analysed, an initial site evaluation model was developed that considers the aforementioned aspects, proposing keys for interpreting the potential for restoration on the basis of the key characteristics that the restored buildings must possess, the facilities they must provide and the external areas (pertaining and agricultural land) to be provided. When possible, this should be achieved through the indication of the potential uses and/or methods for promoting or funding the operation (on the 
basis of the analysed experiences) and the definition of the main current regulations relevant to the case in hand.

The typological analysis of a typical site will explain or rule out possibilities for expansion, in keeping with the original type.

The technological analysis of the current condition will be assessed, and an indication will be made of the technical solutions for preservation or replacement (depending on the case in hand and requirements) $[6,7]$.

The dimensional analysis (of the buildings and their land) will give a suggestion of the relevance or unsuitability of the suggested operation, on the basis of the minimum dimensional standards provided for by the alternative intended forms of re-use.

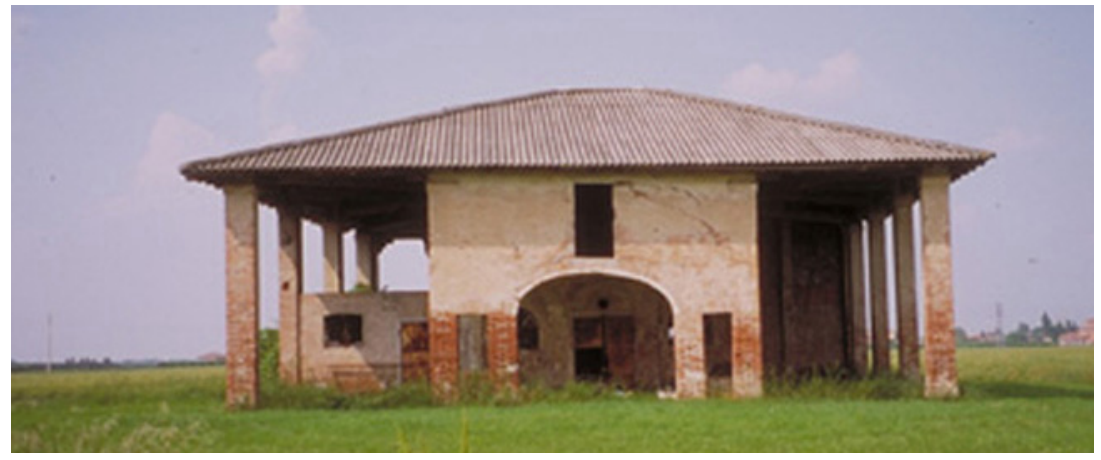

Figure 2: $\quad$ The productive building (knows as "Dotti hayloft").

\section{Survey of rural sites}

Problems linked to the restoration of rural buildings comprise one of the main areas for discussion in terms of town and area planning in the region of Emilia Romagna. The regional authority is aware of the problems linked to the regeneration of the area's heritage. The provincial councillors for agriculture and area planning and the Region of Emilia Romagna have worked together over recent years in order to analyse the visual impact of agricultural and service buildings and come up with methodological tools that can be used by businesses and municipal administrations for the promotion and valorisation of the rural area through its agricultural worth, preserving its natural aspects and landscape. However, there are still many rural buildings that have been abandoned by their traditional users and need to be re-used so as to prevent their rapid deterioration and progressive disappearance.

This subject has led to further study of the complex and related factors in play, together with the survey of rural sites in the Ferrara and Bologna areas, selected on the basis of their typological, architectural and technological characteristics, their accessibility and current use and identifying them on the basis of criteria that make it possible to check the technical and economic feasibility of a new operation on the existing building. 
The buildings involved in the analysis make up an integrated local system and represent a cultural and historic heritage that contributes to the definition of the historical identity of the area they belong to, bearing witness to the civilisation of the context in which they stand. Some of them have been badly restored, some are out of use and abandoned, whilst others are now being used for purposes other than their original intended use.

They mainly comprise farms, agritourisms, nature parks and educational farm sites. The four functions are often all present within the same complex.

The project aims to draw up a complete picture relative to:

- potential use of the analysed complexes;

- different types of building sites present in the area in question;

- technological aspects (with reference to the conservation of original technology and the existence of recent or not-so-recent operations);

- state of preservation;

- owners' interest in investing;

- technical planning opportunities and alternative operations.

All the rural buildings surveyed have specific economic potential for re-use and can be subjected to compatible re-use, political and economic planning strategies, targeted at the economic, architectural and cultural re-evaluation of the property itself.

The main aspects assessed during the rural heritage survey phases include: the operation methods used, those targeted at the restoration of a modest, nonmonumental building of high environmental standing; the analysis of the room types and their modifications; the evolution of regulations and planning control systems and how these have influenced the owners' decisions.

The building components, the structural systems, the technology, the construction solutions and any maintenance, restoration and regeneration techniques adopted in the rural buildings were analysed, whilst reports relative to the landscape/environmental, economic and infrastructure context were also examined.

The analysis of the manufactured articles was based on an on site survey, accompanied by documentary, historical/archive and photographic investigations, direct observation of the state of preservation and questionnaires filled in by the owners. The analysis investigations took place gradually, on the basis of the need to establish the potential for the recovery and regeneration of the complex, in order to check the compatibility of the current use, evaluate alternatives, and consider the suitability of the operation techniques used or necessary for use on the building or part thereof. For every complex, a record was made of the main generators and construction techniques for the types of rural buildings analysis, evaluating the compatibility of the changes or additions made in relation to these and the analysis of the surrounding conditions and the suitability of the operation techniques used and the intended uses identified in relation to the nature and construction characteristics of the buildings in question. 
The analysis phases included:

- the recording of the architectural characteristics specific to the building, that is to say the identification of any noteworthy characteristics in the buildings, important for establishing the restoration plan approach. A well informed operation, targeted at valorising the property, must begin with the recognition of the architectural types and characteristics, the identification of characterising elements, original parts and additions;

- the evaluation of the operation techniques used for the preservation of the architectural components, their transformation and practical adaptation for new uses;

- the evaluation of the compatibility of the spatial and distribution solutions in relation to the current use or proposed alternatives. The idea is that the adopted solutions or those to be adopted respect the morphological and structural characteristic, that is to say that they are based on the rural morphological examples [6];

- the economic evaluation of the operation, that is to say the analysis of the relations between the technical and economic components in the present condition and the forecast use for an initial feasibility assessment;

- the evaluation of regulations and legislation that allow for the preservation of existing architectural heritage of historic value and that permit the re-use of buildings and their economic valorisation, whilst preserving the main architectural and typological characteristics, guaranteeing the quality of the operations and allowing re-use for compatible activities;

- the influence of environmental factors and nearby situations on the potential to valorise the property.

On the basis of the on site investigations and the assessments designed to identify a protection strategy that entails the sustainability of the operation, the research activities are concentrating on the following steps:

- analysis of the morphological, typological and technological characteristics;

- definition of criteria for evaluating the building's suitability for transformation;

- creation of an analytical model for the evaluation of the preservation / maintenance quality;

- evaluation - by homogeneous area - of the quality of the market demand and local requirements;

- definition of a method for directing the owner of the property to be restored towards a rapid interpretation of the property's use and economic potential;

- definition of objective and distinctive quality/versatility parameters relative to the building.

\section{Le Pradine farm - Nature Reserve: an example of best practice}

Le Pradine farm is an example of a complex that has achieved the re-use sustainability objective. It takes its name from an old map dating back to the $19^{\text {th }}$ century and is located in Mirabello, $15 \mathrm{~km}$ from Ferrara city centre. 
The entire complex is located in a larger area known as "Oasi Boscosa", covering a surface area of 450 hectares.

The farm was founded in 1992 and is built around the central body of the Tenuta Sassa. It began operating a series of agricultural activities (animal husbandry, wine production, fruit growing), together with an agritourism and an educational farm located in a series of smaller sites, supporting the main architectural nucleus. Every site is a model of the local architectural heritage and therefore the owner operated in keeping with the traditional typology and techniques.

The sites in the complex, observed and studied in depth during the research, preserve similar typological and architectural features. They are "open" sites, comprised of two main bodies such as the farmhouse and the hay barn/stables. They always have outbuildings such as cottages, woodsheds and ovens. The rural buildings are essentially made of brick and wood, materials that were readily available in the area [3].

All the sites currently being renovated due to a change of use are in an excellent state of preservation, thanks to the owner's continuous attention to carrying out small ordinary maintenance work.

The history of the buildings and rural properties still present on the farm today, which date back to the early $19^{\text {th }}$ century and housed farmers and their families, provide a cultural picture of the characteristics of agricultural buildings of the time. The passion and entrepreneurial spirit of the owners have led to the creation of a rare example of conservation of a typical Ferrara countryside environment.

The fascinating history of this area, the current use that respects the local flora and fauna, and the re-use and maintenance of the various rural sites, using technology in keeping with that used in the past, have made this complex stand out amongst the many were examined and studied as part of the Villas project.

The criteria that led to the identification of Le Pradine as an example of best practice can be summed up as follows:

- the typological, architectural and technological interest of the sites making up the complex;

- the low environmental impact of the production systems adopted;

- the importance of the complex in the area;

- the articulation of the complex and the various different uses therein;

- the communicative ability and interest of the owner in re-launching his holding and contributing to the research;

- the hospitality possibilities offered to users;

- the good infrastructure;

- the procedures followed to obtain funding;

- the compatibility of the current use with the building that houses it and the surrounding land;

- the economic compatibility of the operation (on the basis of the analysis of costs/profits).

The desire to boost profits is certainly behind the entrepreneurial spirit that led the owner to invest in the farm and valorise the architectural complex and 
surrounding land. However, the owner also demonstrated a certain awareness of the rural environment. The secondary objectives that arose after the decision to invest, comprise: the desire to boost the city/country relationship, to promote interest in and awareness of the environment and farming, to promote awareness of farm produce on a regional level and to make the public more aware of environmental problems (through the nature reserve).

The objectives have been achieved so well that there has been an increase in profits, accompanied by the preservation of the architectural quality and environmental valorisation of the complex, through the creation of paths and tracks through the reserve, and crop growing compatible with the intended use and location.

The interest demonstrated by the owner in the research is linked to his desire to invest in future projects, so as to be able to cope with the high degree of competition in the area. These projects include: the organisation of educational activities within the complex; the creation of a museum of peasant culture; the protection of the quality of the offer through controlling the activities and proposing medium/long-term projects; the improvement of initiative coordination within the structure; further diversification of the offer, through the proposal of cultural initiatives (museum of peasant art) and new economic activities (wine cellar with wine and vinegar sales); the involvement of a diverse range of users (increasing the involvement of schools by organising courses); charging a fee for visits to the nature reserve, thus increasing profits.

\section{References}

[1] Massaretti, P.G., Insediamento rurale e ambiente della pianura deltizia, in AA.VV. Il Parco del delta del Po. Studi e immagini, Spazio Libri Editori: Ferrara, Italia, pagg. 174-199, 1990.

[2] Gaiani, A., Caratteri tipologici e morfologici degli insediamenti rurali nella pianura emiliana, in Costruire in Laterizio, n.47 settembre-ottobre 1995, Di Baio Editore SpA: Milano, Italia, pagg. 332-343, 1995.

[3] Zaffagnini, T., Un tipo edilizio da salvare: la stalla-fienile della pianura bolognese, in Costruire in Laterizio, n.47 settembre-ottobre 1995, Di Baio Editore SpA: Milano, Italia, pagg. 344-350, 1995.

[4] Zaffagnini, M. (a cura di), Le case della grande pianura, Alinea Editrice: Firenze, Italia, pagg. 287, 1997.

[5] Zaffagnini, T., I materiali e le tecniche costruttive, in Zaffagnini, M. (a cura di), Le case della grande pianura, Alinea Editrice: Firenze, Italia, pagg. 235-282, 1997.

[6] Boeri, A. (a cura di), Tecnologie per il recupero dell'edilizia rurale, Minerva Edizioni: S. Giorgio di Piano (Bo), Italia, pagg. 333, 2002.

[7] Zaffagnini, T., La valutazione esigenziale negli interventi di recupero dell'edilizia rurale, Cap. II.8, in Boeri, A. (a cura di), Tecnologie per il recupero dell'edilizia rurale, Minerva Edizioni: S. Giorgio di Piano (Bo), Italia, pagg. 107-113, 2002. 